\title{
BIBECHANA
}

A Multidisciplinary Journal of Science, Technology and Mathematics

ISSN 2091-0762 (online)

Journal homepage: http://nepjol.info/index.php/BIBECHANA

\section{Synthesis and design of laboratory device from proton conducting block copolymer membrane}

\author{
Shankar P. Khatiwada ${ }^{1}$, Amar P. Yadav ${ }^{1}$, Werner Lebek ${ }^{2}$, Jean Marc Saiter ${ }^{3}$, \\ Rameshwar Adhikari ${ }^{1, *}$ \\ ${ }^{1}$ Central Department of Chemistry, Tribhuvan University, Kathmandu, Nepal \\ 2 Institute of Physics, Martin Luther University Halle-Wittenberg, Halle/Saale, Germany \\ ${ }^{3}$ AMME-LECAP International Laboratory EA 4528, Université de Rouen, \\ 76801 Saint Etienne du Rouvray Cedex, France \\ *Corresponding author: E-mail : nepalpolymer@yahoo.com \\ Article history: Received 22 October, 2012; Accepted 7 November, 2012
}

\begin{abstract}
The butadiene units of polystyrene-block-polybutadiene-block-polystyrene (SBS) triblock copolymer were subjected to epoxidation and subsequent sulphonation in order to prepare proton conducting ionomer membrane. The products were characterized by different techniques such as atomic force microscopy, Fourier transform infrared (FTIR) spectroscopy and electron microscopy. A simple laboratory device was developed to carry out the tests on proton conductance ability of the prepared ionomer membrane. The experiments demonstrated that the prepared membrane excellently performed as proton conducting membrane.
\end{abstract}

Keywords: Block copolymer; idation; Sulphonation; FTIR spectroscopy; Electron microscopy; Proton conducting membrane

\section{Introduction}

Block copolymer molecules self-assemble in the melt as well as in the solid state into a large variety of periodic nanostructures through intra-molecular phase separation. The periodicity of these structures lies between the 10-100 $\mathrm{nm}$ which enables precise control of their mechanical properties over the wide range $[1,2]$.

Styrenic copolymers, such as polystyrene-block-polybutadiene-block-polystyrene (SBS) and polystyreneblock-polyisoprene-block-polystyrene (SIS) triblock copolymers constitute an important class of thermoplastic elastomers [1-3]. Both SBS and SIS are non-polar and non- conducting polymers. However, sometimes it is useful to increase their molecular polarity by inserting some functional groups for several specific applications. Also the functionalization of the copolymer matrix with epoxy group and 
fabricating the blends with metal compounds leads to the formation of a novel conducting materials [4]. Further, the unique properties arise in such nanostructured polymers by incorporating functional groups into polymers via sulfonation. These features have led to an exploration of different applications for sulfonated block copolymers, such as in ion exchange resins, batteries, sensors etc. [5-7].

The aim of present work is to chemically modify an SBS triblock copolymer in such a way that it performs as a flexible conducting ionomer membrane that may be useful in sustainable fuel cell applications. It is further aimed at developing a simple laboratory tool to demonstrate the ability of the prepared ionomer film for ion conductivity.

\section{Experimental Section}

\section{Materials}

The polymer used in this work was polystyrene-block-polybutadiene-block-polystyrene (SBS) triblock copolymer (commercial name: Kraton D1184 CS) with 70 wt. \% polybutadiene and having weight average molecular weight $(\mathrm{Mw})$ of $310,000 \mathrm{~g} / \mathrm{mol}$. Toluene $(99 \%)$, formic acid $(85 \%)$, polyethylene glycol (PEG-400) and hydrogen peroxide (30\%-w/v), methanol (99.5\%), sodium bisulphite (NaHSO3), sodium bicarbonate $\left(\mathrm{NaHCO}_{3}\right)$, tetraethyl-ammonium bromide (TEAB), $\mathrm{N}-\mathrm{N}$ dimethyl aniline (DMA) and different inorganic compounds were purchased from local market and used as received.

\section{Synthesis of Epoxidized Block Copolymer (eSBS)}

The SBS block copolymer was epoxidized to different degrees following the standard procedures discussed in literature [8-10]. The epoxidation reaction is described in Scheme 1.

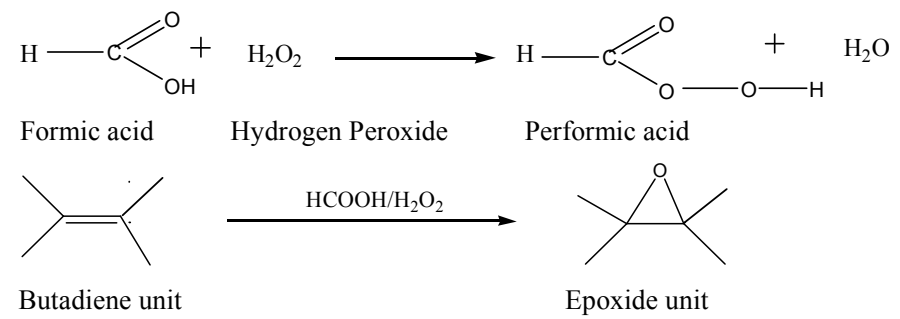

Scheme 1. Scheme of epoxidation reaction of styrene/butadiene block copolymer; the butadiene block undergoes chemical modification resulting in epoxide groups.

The mass fraction of epoxy groups of epoxidized polystyrene-block-polybutadiene-block-polystyrene (ESBS) block copolymer was determined by directly titrating the $\mathrm{HCl}$-acetone (1:80 ratios by volume) solution of the polymer by standardized methanolic caustic soda solution [10].

\section{Preparation of Sulphonated Block Copolymer (sBCP) Ionomer}

eSBS sample having $80 \%$ epoxidation level was dissolved in toluene to prepare $10 \%$ (mass by volume) solution and subsequently sulphonated using tetraethyl ammonium bromide (TEAB) as phase transfer catalyst and dimethyl aniline (DMA) as ring-opening catalyst in presence of $\mathrm{NaHSO}_{3}$ and $\mathrm{Na}_{2} \mathrm{SO}_{3}$ solutions 11. The synthetic procedure is illustrated in Scheme 2. The specimen of each sample was prepared by solution casting using toluene as solvent. The sample was dissolved in the solvent to make its $5 \%$ solution and poured into a Petri dish. The solvent was allowed to evaporate slowly at room temperature (approximately $25^{\circ} \mathrm{C}$ ) to form a uniformly thick films. The resulting film was dried to constant weight. Additionally, nanocomposite film with $5 \mathrm{wt} .-\%$ organically modified layered silicate 


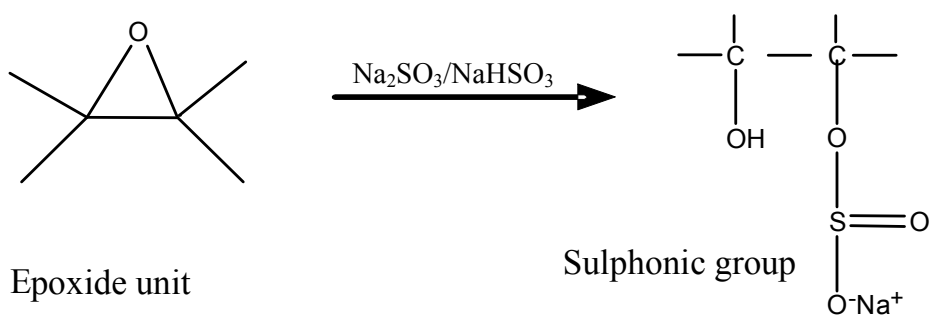

Scheme 2. Scheme showing the formation of ionomer from eSBS through ring opening reaction

(Nanofil 5, Südchemie, Munich) was also prepared using the same procedure for polymer/filler mixture.

\section{Test of Ionomer as Proton Conducting Membrane}

In order to perform the laboratory test for proton conductivity through the ionomer film, a simple cell having two compartments was designed, those being separated by the ionomer membrane. During the experiment, the ionomer membrane having $25 \%$ sulphonation of available epoxy groups was taken to separate the two half cells. Both the cells were provided with sulphuric acid solution $\left(2 \mathrm{M} \mathrm{H}_{2} \mathrm{SO}_{4}\right.$ in $20 \mathrm{~mL}$ of distilled water). The $\mathrm{H}+$ concentration of one of the compartments was varied by the progressive addition of concentrated sulphuric acid into it and keeping the concentration of another compartment constant. The solution was thoroughly mixed and the overall cell potential was measured by completing the circuit and recording the change in potential caused by variation in concentration of $\mathrm{H}+$ ion in the half cells with the aid of a digital multimeter.

The device thus constructed represents a concentration cell whose total electromotive force (EMF) changes with the variation in electrolyte concentration of the half cells. The cell EMF, which depends upon the acid concentration difference in the half cells, will be given by the corresponding Nernst equation:

$$
\mathrm{E}_{\text {Cell }}=-\frac{\mathrm{RT}}{\mathrm{F}} \ln \frac{\left[\mathrm{H}^{+}\right]_{\mathrm{A}}}{\left[\mathrm{H}^{+}\right]_{\mathrm{B}}}
$$

where the symbols have usual meanings.

\section{Characterization Techniques}

The morphological details of the SBS copolymer was inspected by means of tapping mode atomic force microscopy (AFM, Multimode, Digital Instruments, Santa Barbara, CA) using the surface of a thin film. Scanning electron microscopy (SEM) (JSM 6300, JEOL) was used to visualize the structural details of the ionomer samples using freshly cryo-fractured surfaces. The fracture surface was sputtered coated with thin gold film to avoid charging and irradiation damage during the SEM inspection.

Fourier Transform Infrared (FTIR) spectroscopy and transmission electron microscopy (TEM) were used for the characterization of the structure and morphology of the sample. FTIR spectra were collected by a Perkin Elmer FTIR 2000 spectrophotometer in ATR mode by collecting and averaging 32 scans over a range of $400 \mathrm{~cm}-1-4000 \mathrm{~cm}-1$ at a resolution of $4 \mathrm{~cm}-1$. Thermal studies were performed by means of thermogravimetric analysis (TGA) using TGA 209 balance (Netzsch, Germany) in nitrogen atmosphere from 10 to $250{ }^{\circ} \mathrm{C}$ at a heating rate of $10{ }^{\circ} \mathrm{C} / \mathrm{min}$. 


\section{Results and Discussion}

\section{Characterization of Block Copolymers Morphology and Degree of Epoxidation}

Fig. 1 presents the AFM phase image of thin film of the block copolymer used in this study. The film was prepared by dip coating technique following by vacuum annealing at $120^{\circ} \mathrm{C}$ for 24 hours.
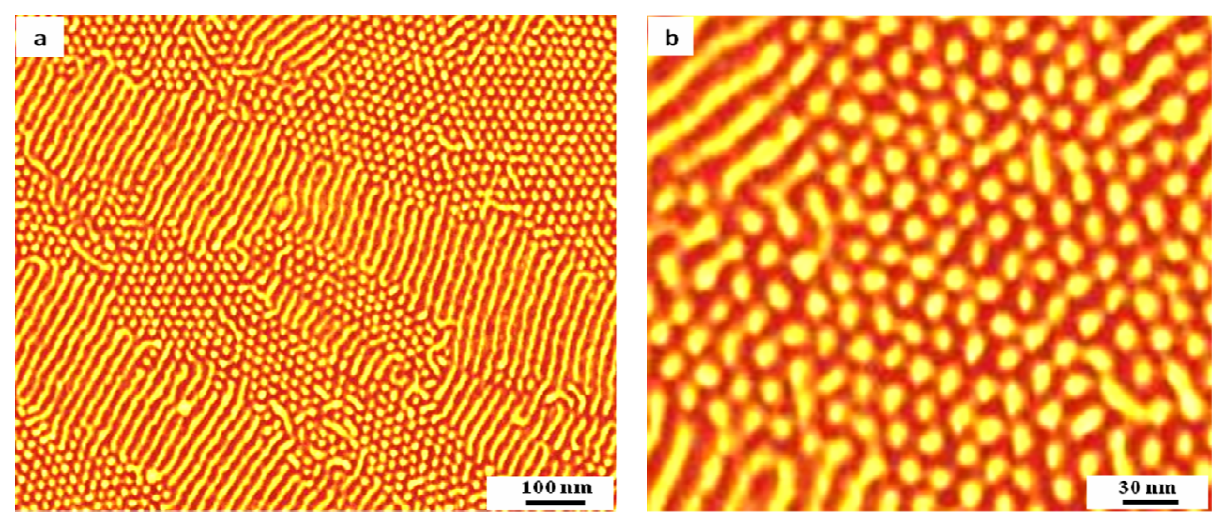

Fig. 1: Lower (left) and higher (right) tapping mode AFM phase image of SBS triblock copolymer used in this work.

The morphology of the pristine copolymer comprises ordered cylindrical domains of polystyrene (bright appearing in the phase image) dispersed in the matrix of polybutadiene (dark appearing in Fig. 1), the latter being the majority component of the block copolymer. The chemical modification intended in the present work will take place in the polybutadiene matrix. Hence, it may be expected that, in particular, the matrix property of the copolymer may be modified.

The degree of epoxidation is defined as the percentage of repeating units of the block copolymer that has been epoxidised. Epoxidation process was conducted several times by varying the reaction times at room temperature (about $25^{\circ} \mathrm{C}$ ) and the extent of epoxidation was determined. The results are presented in Fig. 2.

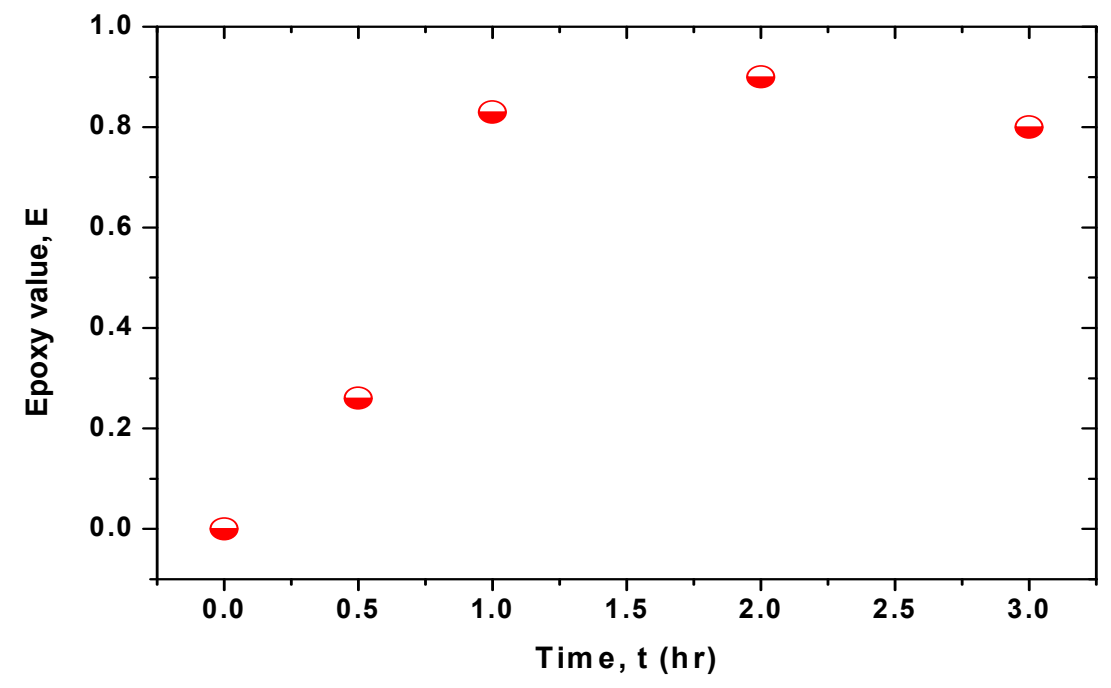

Fig. 2: Plot of epoxy level of the block copolymer as a function of time. 
Initially, the epoxy level remains zero, as expected. After half an hour, the epoxy level reaches over 0.2 (i.e., 0.2 equivalent mole of SBS is converted to eSBS). The SBS to eSBS conversion increases rapidly under given condition and reaches maximum of about $90 \%$ conversion after 2 hours after which epoxidation content practically levels off.

The attempts were also made to carry out the epoxidation reactions at higher temperatures up to $50{ }^{\circ} \mathrm{C}$. However, the output was not satisfactory as the solvent evaporated rapidly making it difficult to handle the polymer solution towards favorable yield.

The FTIR spectra of BCP, eSBS and sSBS (ionomer) are compared in Fig. 3(a,b). A part of the spectrum of interest in Fig. 3a has been magnified in Fig. 3b. The peak at $910 \mathrm{~cm}-1$ is characteristic of the $\mathrm{C}=\mathrm{C}$ linkages present in the butadiene units of the block copolymer and corresponds to the trans $-\mathrm{C}=\mathrm{C}$ double bonds vibrations of 1,4-polybutadiene [11,12].
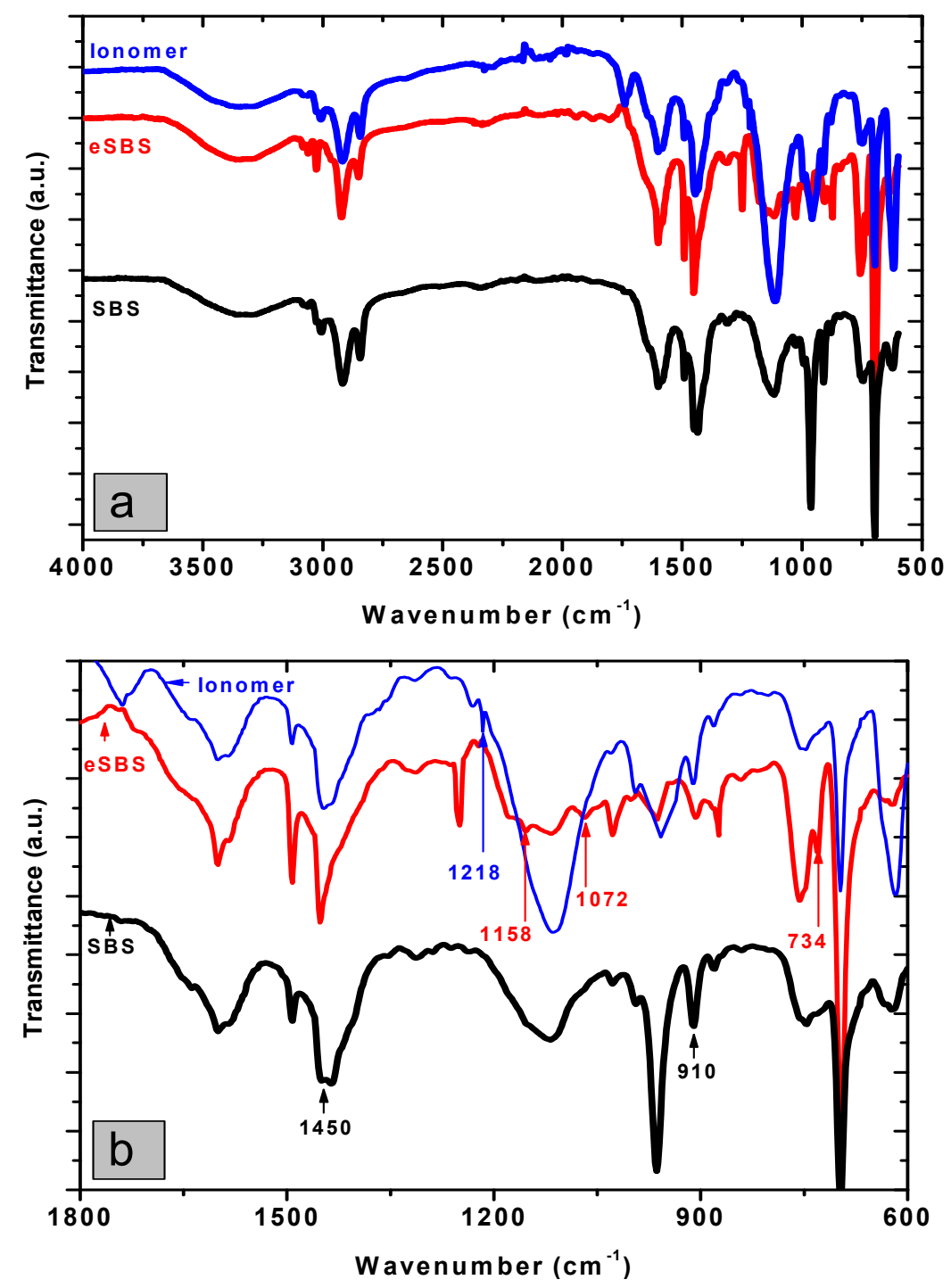

Fig. 3: FTIR spectra of different specimens (SBS, eSBS and ionomer) investigated in present work; a part of spectrum given in top has been magnified at the bottom figure. 
In the spectrum of eSBS, additional peaks, not present in the SBS copolymer, appear. Among them, the peaks centered at $734 \mathrm{~cm}-1,1072 \mathrm{~cm}-1$ and $1158 \mathrm{~cm}-1$ can be assigned to the epoxy ring stretching [8,11] and attest the insertion of epoxy groups in the block copolymer leading to the formation of epoxidized eSBS. In case of ionomer film, those peaks disappear and a distinct peak centered at $1218 \mathrm{~cm}-1$ appears indicating the sulfonation of the eSBS into its sulphonated version (i.e., sSBS).

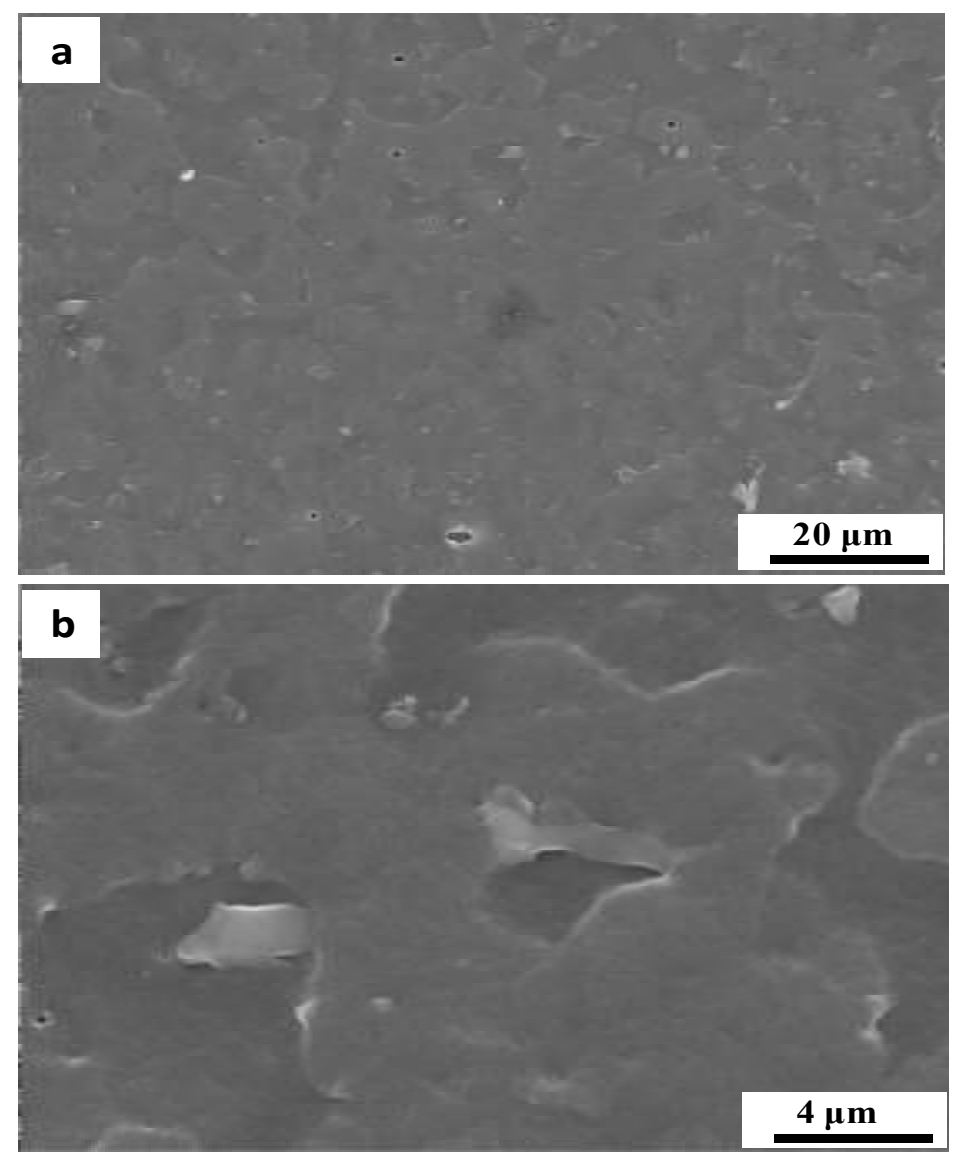

Fig. 4: Lower (top) and higher (bottom) magnifications of scanning electron micrographs of the sulphonated SBS ionomer.

Unlike literature reports in similar systems, no remarkable absorption peak was found around 1,725 cm-1 implying the absence of the side reactions leading to the formation of carbonyl $(-\mathrm{CO})$ group. However, peaks around 3,500 $\mathrm{cm}-1$, indicates the presence of hydroxyl $(-\mathrm{OH})$ groups, which might have resulted from moisture and residual methanol used in the coagulation of the epoxidised products [13].

Scanning electron micrographs of different magnification of the sSBS ionomer is presented in Fig. 4. The micrographs depict a characteristic morphology of an elastomeric material (or rubber) with flat areas over a wide range. However, on the fracture surface, small islands of irregular shapes appear to be embedded suggesting that there is a sort of phase separation in the ionomer sample.

Let us recall the fact that only approximately $25 \%$ of the butadiene units of the SBS were converted into the epoxidized units which were later sulphonated. The possible reason for segregation of different components as indicated in Fig. 4 could be the incompatibility of the sulphonated copolymer with the neat matrix. Similar behavior was also observed in acrylated styrene/isoprene based triblock copolymer [13]. 


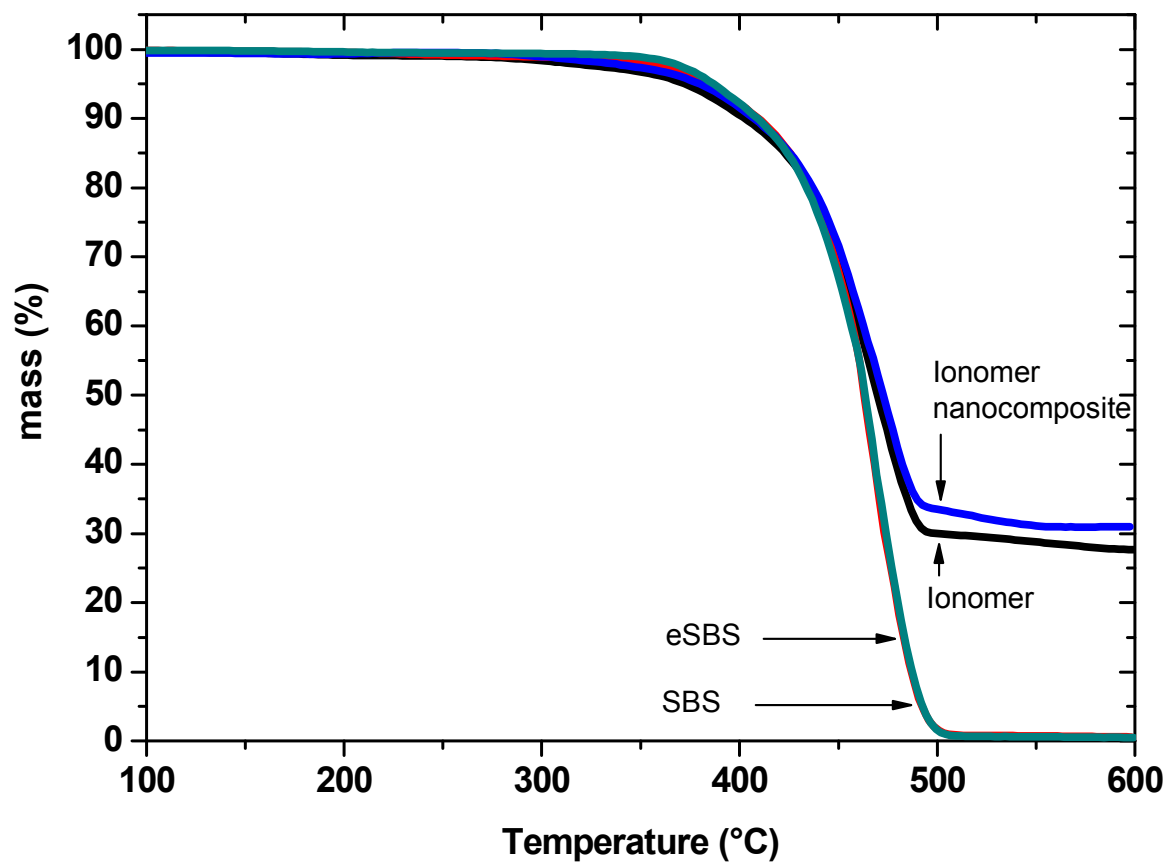

Fig. 5: Thermogravimetric plots of different specimens studied in this work compared with a nanocomposite of the ionomer with 5 wt.-\% layered silicate.

\section{Thermal Characterization by Thermogravimetric analysis}

The thermal stability is an important property of materials which primarily depends on the nature of the materials, chemistry of the constituents and the processing history. Most of the organic compounds degrade at lower temperatures compared to the inorganic compound. Thermogravimetric analyses (TGA) show that SBS and eSBS polymers are not much different with respect to the thermal stability, both of them showing mass loss process beginning at $300^{\circ} \mathrm{C}$.

Fig. 5 shows that SBS and eSBS undergo complete degradation at $500{ }^{\circ} \mathrm{C}$. The TGA curves show one step decrease in their mass, Fig. 5. In ionomer, there is over $20 \%$ residual mass due to the presence of ionic $-\mathrm{SO} 3 \mathrm{Na}$ groups which form the tiny ionic aggregates attached to the organic mass, possibly responsible for the stability of the ionomer. Similarly, upon addition of 5 wt.-\% nanofiller such as Nanofil-5 to the ionomer, the residual mass again increased. The reasons of these enhancements in residual masses are not well understood; and more experiments are required to clarify these issues.

\section{Laboratory Test of Ionomer Films as Proton Conducting Membrane}

As mentioned in the experimental section, a simple device was constructed to test the ability of the ionomer film as proton conducting membrane. The results are shown in Fig. 6, in which the variation of the cell EMF as a function of $\mathrm{H}+$ ion concentration in one of the cell compartments is plotted. The EMF increases gradually (shown by filled symbols in Fig. 6) with the increase in the $\mathrm{H}+$ ion concentration, as may be expected to the concentration cell. In order to evaluate the reproducibility of the results, similar sets of experiments were performed using the polymer membrane with 50 and $100 \%$ sulphonation (results not shown here).

For all the experiments, nearly identical results were observed on using Agar-Agar gel based salt bridge (see the data shown by open symbols in Fig. 6) instead of the membrane. These observations demonstrate 


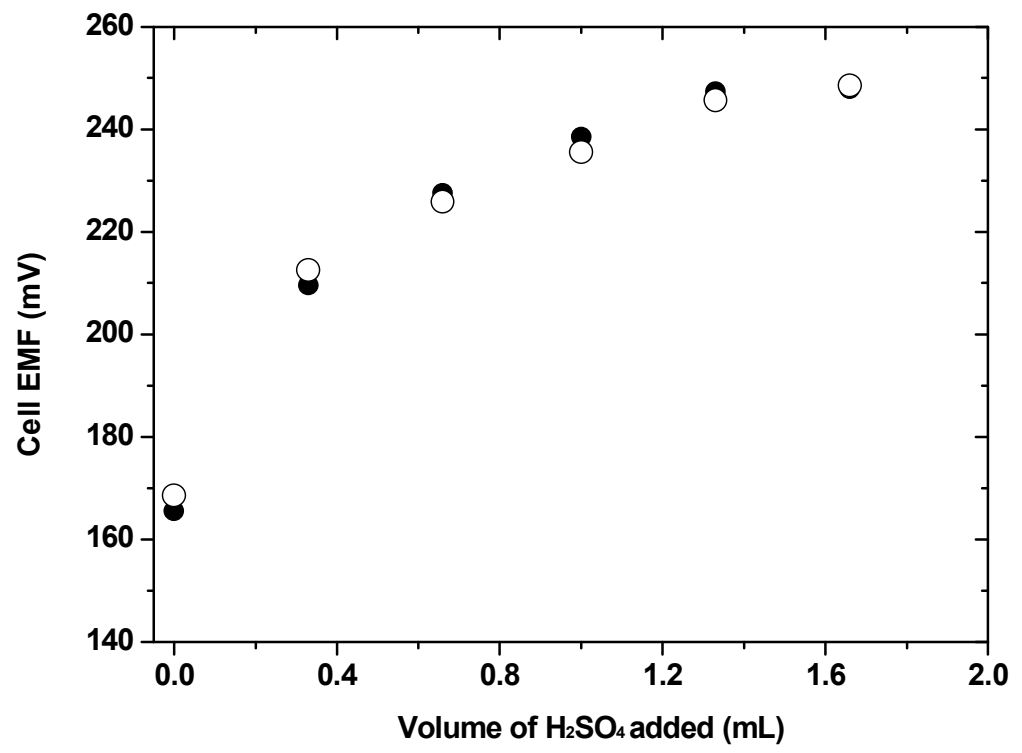

Fig. 6: Variation in total cell potential due to change in the concentration of $\mathrm{H}+$ ions in cell $\mathrm{B}$ presented in Fig. 3; the full symbols stand for the potential measured with ionomer membrane while open symbols represent the values measured with salt bridge.

that there is an unhindered flow of the $\mathrm{H}+$ ions from one compartment of the cell to another through the sSBS ionomer membrane thus confirms its proton conducting ability of the sSBS ionomer film.

\section{Concluding Remarks}

The commercially available polystyrene-block-polybutadiene-block-polystyrene (SBS) triblock copolymer was subjected to epoxidation reaction using performic acid generated in situ as a result of reaction between formic acid and hydrogen peroxide. The products were characterized by different techniques such as FTIR spectroscopy, electron microscopy. The ESBS was successfully modified into different ionomers. The formation of ionomer was characterized by proton conductivity measurement. The conductive ionomer was formed due to the presence of $-\mathrm{SO} 3 \mathrm{H}$ group on which passage of ions through ionomer films took place. Ionic conductivity was found to increase with the increase of degree of sulfonation in the ionomer.

\section{Acknowledgements}

The authors are thankful to Kraton Polymers, Houston, TX for the supply of block copolymer used in this work. Mr. Netra Lal Bhandari, Mr. Santosh Khanal, Mr. Rajesh Pandit and Dr. Megh Raj Pokharel are thanked for fruitful discussions and various experimental supports.

\section{References}

[1] I. Hamley, The Physics of Block Copolymers, Oxford Publishers, London (1998).

[2] R. Adhikari and G. H. Michler, Progress in Polymer Science, 29 (2004) 949.

[3] G. Holden, Understanding Thermoplastic Elastomers,Hanser, Munich (2000).

[4] E. Dalas, S.N. Koklas, E. Vitoratos, S. Sakkopoulos, J. Materials Science Letters, 12 (1993) 497.

[5] J. P. Gouin, C. E. Williams, A. Eisenberg, Macromolecules, 22 (1989) 4573. 
S. P. Khatiwada et al. / BIBECHANA 9 (2013) 50-58: BMHSS, p. 58 (Online Publication: Nov., 2012)

[6] R. A. Weiss, A. Sen, C. L. Willis, L. A. Pottick, Polymer, 32 (1991) 1867.

[7] T. Schultz, S. Zhou, K. Sundmacher, Chemical Engineering and Technology, 24 (2001) 1223.

[8] R. Pandit, J. Giri, R. Lach, W. Grellmann, G. H. Michler, B. Youssef, J. M. Saiter, R. Adhikari, Macromolecular Symposia, 315 (2012) 152.

[9] J. M. Dean, P. M. Lipic, R. B. Grubbs, R. F. Cook, F. S. Bates, J. Polymer Science Part B: Polymer Physics, 39 (2011) 2996.

[10] H. Li, X. Zeng, and W. Wu, J. of Elastomers and Plastics, 40 (2008) 317.

[11] B. C. Johnson, I. Yilgor, C. Tran, M. Iqbal, J. P. Wightman, D. R. Lloyd, J. E. McGarth, J. Polymer Science: Part A: Polymer Chemistry, 22 (1984) 721.

[12] R. Pandit, A. Berkessel, R. Lach, R. Adhikari, Nepal Journal of Science and Technology, 13 ( 2012 ) 81.

[13] R. Adhikari, S. Khanal, A. Shakya, G. H. Michler, B. Youssef, J. M. Saiter, Materials Research and Innovation, 16 (2012) 356. 